\title{
CALL's effectiveness in the process of second language learning
}

Rawsan Hedo, MA TESOL student

rawsan.hedo@westcliff.edu

\begin{abstract}
This paper is presented to illustrate the importance of technology in education. It discusses several factors playing a significant role in the teaching and learning processes. This paper shows how contemporary learners apply various strategies of learning implementing technology for support. This study considers the advantages and disadvantages of utilizing technology in educational settings by examining current evidence-based research and different points of view.
\end{abstract}




\section{Introduction}

One of the contemporary terms popular in technology is Computer Assisted Language Learning (CALL). This acronym refers to any operation in which a learner uses a computer to improve and learn a second language. Hubbard (2009) illustrates that CALL does not only include desktop or laptop devices, but includes other devices such as mp3 players, mobile phones, whiteboards, smart boards, and DVD players.

At the beginning of technology usage in the classroom, some educators criticized the information technology (IT) field due to the non-universal implementation and the restriction of access to technology. (Hubbard, 2009) states, "similarly, others have criticized the field for being too connected to general education rather than focusing on the unique qualities of language learning" (p. 93).

The earliest projects of CALL began in the 1950s and 1960s. Initial attempts appeared to utilize technology after the invention of the computers in only a few subject areas to aid learning acquisition. By the 1980s, personal computers started spreading to the general public and they were utilized to support learners at all levels in many different subject areas, including language learning.

These attempts continued to develop and expand CALL projects and usage. It was observed (through designing and evaluating numerous projects and programs conducted by scholars) that there is an emphasis on the unique qualities of CALL. Among the programs evaluated were online courses, software programs, and designs. General approaches of CALL included: checklists, methodologies, frameworks, indices, and applications of second language acquisition (SLA) principles (Hubbard, 2009).

This paper seeks to explore the benefits and challenges of CALL, as well as the reasons behind why educators would or would not implement CALL resources into their courses. CALL is defined according to personal experience and whatever definition may be used given the learning environment and program. The main focus of CALL, learning language through different applications needing devices such as cellphones, computers and iPads, is the same no matter what program or system is being used to teach. Zhytska (2012) states that, "It is necessary to understand the huge possibilities of the Internet application in the foreign 
language learning and teaching to provide wider opportunities for students to communicate effectively with a lot of people around the world" (p. 25).

\section{Discussion}

Advantages

I use CALL in my classes because of the advantages my students experience while learning. When I see my students using CALL individually or sharing their ideas with others after having experiences of using different websites and applications, I see firsthand the value of utilizing CALL. Other advantages appear as well. I find my students' motivation increases by using different games and activities on the computer which assists them in developing their four critical language skills. CALL helps students practice individualization, which refers to choosing which skills to develop and which courses to take.

Another benefit of using CALL in the classroom that causes students to interact with teachers is by sending them their own individuated tasks through emails.

One day, I divided my class into two groups. The first group was allowed to use computers to search for information regarding an assigned topic. The second group was not allowed to use computers at all, but they were allowed to go to the library and choose any book they needed for their search on the same topic. I gave each group 20 minutes to do their research. After that, I switched the groups. When the task was completed, I asked my students, "Which way was easier? Why? Which way do you prefer? Why?" Most of the students preferred using technology because it gave them easy access to more resources with less effort. Disadvantages

A challenge with using technology such as CALL is the rising costs to the school or educational institution since using computers would become a necessity. Using CALL may make learners confused about some information because there are no specific topics to be taught. Traditional books focus on limited topics. In Iraq, only private schools and a limited number of public schools are able to implement CALL. The lower income schools and students from low income families cannot usually afford a computer. It can cause unfair competition and uneven educational environments for those poorer schools and students. Expensive hardware and 
software also becomes a huge obligation for schools and parents. Implementing CALL requires more teachers, more training, and more time in class schedules.

In my opinion, to overcome or reduce the digital divide, I can suggest the following:

1. The government should provide access to free Internet service.

2. The government should provide one computer per home.

3. The government should provide computers for computer labs in each high school and higher education institution.

4. The government should provide laptops for rural community schools and students.

All these above-mentioned recommendations can be achieved by coordination between local and national governments and global organizations which support solutions to educational challenges. If so, they can create fairer communities and more equitable access to technology in education around the world.

Purpose of Technology

Taylor (2014) posed the possibility of uses of the computer in three different settings: tutor, tool, and tutee. Taylor (2014) was the first to distinguish between these three terms and roles as he explained, "When the computer is used as a tutor, it temporary takes the place of a teacher by providing instruction and guidance. When used as tool, it has no teaching attributes but facilitates instruction. As tutee, the students program the computer" (Chritison \& Murray, 2014, p.39).

Computer as Tutor

To depend on computers for lessons, computers should be programmed by experts in all subjects. Programming computers often wastes time because it needs days of preparation for a one-day lesson plan. Also, the computer then becomes the center of instruction, or the only teacher in the class by automatically presenting subject materials and any other resources related to that lesson. There is, in contrast, an advantage of using computers when considering the entire presence of students. This advantage is that, "With appropriately well-designed software, the computer tutor can easily and swiftly tailor its presentation to accommodate a wide range of student differences" (Taylor, R. 1983). 


\section{The Computer as Tool}

To design a class by using computers as a tool, there needs to be programs which support each served class. For example, I sometimes, connect my teaching/learning activity with using computers especially when my students are using their laptops to search a specific topic for a presentation or to make calculations when solving math problems. In this case, teachers and students may save time and preserve intellectual energy by transferring the necessary but routine tedious clerical tasks to the computer. Using computers either as tutors or as tools improves and enriches classroom learning. It does not require students or teachers to have heightened skills or retrain.

Based on the points above, there are differences between using computers as tools and as tutors in the following cases:

1. Using computers as tutors requires more hours to be well-organized because humans are much more flexible than any machine, even a computer.

2. Designing a lesson plan to be delivered by a teacher requires less time than to be delivered by a computer because teachers can delete some details that they think are not important or adapt spontaneously during a lesson if need be.

3. When the computer is used as a tutor, scaffolding is needed to achieve careful sequencing with each component building on the previous one. Then explicit instructions for learners to practice the language themselves are needed.

4. In contrast, when the computer is used as tool, this interaction may be achieved through human to human connections using discussion lists, emails, and VOIP (Chritison \& Murray, 2014). 


\section{REFERENCES}

Christison, M., \& Murray, D. E. (2014). What English language teachers need to know: Designing curriculum. New York: Routledge Taylor \& Francis Group.

Indrawati, E. D. (2009). Advantages and disadvantages of CALL (computer assisted language learning). Retrieved from https://efidrew.wordpress.com/2008/08/01/assignment-4article-on-call/

Hubbard, P. (2009). General introduction: In computer assisted language learning. London: Routledge.

Improving the effectiveness of language learning: CLIL and computer assisted language. (2014). European Commission. Retrieved from http://ec.europa.eu/dgs/education_culture/repository/languages/library/studies/clilcall_en.pdf

Nordrum, A. (2016, April 14). 3 ways to bridge the digital divide. Retrieved from http://spectrum.ieee.org/tech-talk/computing/networks/3-ways-to-bridge-the-digitaldivide

Taylor, R. (1983). The computer in the school: Tutor, tool, tutee. New York: Teachers College Press.

Zhytska, S. A. (2012). Computer assisted language learning. Information Technology and Security, 2(2), 25-33. 